\title{
Orbicularis Oculi Muscle Size and Function: Exploring the Influence of Aging and Exercise Training
}

\author{
Takashi Abe ${ }^{1,2,3, *(D)}$ and Jeremy P. Loenneke ${ }^{1}$ \\ 1 Department of Health, Exercise Science, and Recreation Management, Kevser Ermin Applied Physiology \\ Laboratory, The University of Mississippi, Oxford, MS 38677, USA; jploenne@olemiss.edu \\ 2 Graduate School of Health and Sports Science, Juntendo University, Inzai, Chiba 270-1695, Japan \\ 3 Institute of Trainology, Fukuoka 810-062, Japan \\ * Correspondence: t12abe@gmail.com; Tel.: +1-(662)-915-5521; Fax: +1-(662)-915-5525
}

Citation: Abe, T.; Loenneke, J.P. Orbicularis Oculi Muscle Size and Function: Exploring the Influence of Aging and Exercise Training. Cosmetics 2021, 8, 29. https:// doi.org/10.3390/cosmetics8020029

Academic Editor: Enzo Berardesca

Received: 11 March 2021

Accepted: 13 April 2021

Published: 14 April 2021

Publisher's Note: MDPI stays neutral with regard to jurisdictional claims in published maps and institutional affiliations.

Copyright: (c) 2021 by the authors. Licensee MDPI, Basel, Switzerland. This article is an open access article distributed under the terms and conditions of the Creative Commons Attribution (CC BY) license (https:// creativecommons.org/licenses/by/ $4.0 /)$.

\begin{abstract}
The orbicularis oculi muscle is the sphincter muscle of the eyelids that blinks and closes the eyes. In this review, our aim was threefold: (1) to introduce the performance characteristics of blinking activity in young and older adults, (2) to discuss the influence of aging on the orbicularis oculi muscle in healthy adults, and (3) to provide information about the effect of facial exercise training on the orbicularis oculi muscle. To achieve the purpose of this review, a search using two electronic databases (PubMed and Scopus) and a search engine (Google Scholar) was conducted. The amplitude and peak velocity of spontaneously blinking behavior, which is an index of muscle function of the orbicularis oculi, appear to be affected by aging. The muscle thickness of the orbicularis oculi tends to be low in older adults, but there are issues that need to be examined further, such as differences in sex and measurement positions. There was no study on the effect of exercise training; however, the results of a highly trained man indicate that the orbicularis oculi muscles might elicit muscle hypertrophy through non-traditional resistance exercise.
\end{abstract}

Keywords: aging; blink; facial exercise; facial muscle; muscle thickness; ultrasound

\section{Introduction}

Cross-sectional studies have suggested progressive age-related declines in muscle size and function in humans. For example, whole-body skeletal muscle volume (mass) measured by magnetic resonance imaging (MRI) was lower in older men and women than in their young counterparts [1]. These results are also supported by a 15-year longitudinal study using MRI [2]. In the human body, there are approximately 600 muscles, when counting the right and left muscles of the same name along with the muscles between the ribs and vertebrae [3]. However, not all of these muscles appear to change at the same rate with age. Cross-sectional studies using ultrasound have found that some but not all muscles differ in size across age groups [4,5]. In the facial muscles, some research reported the influence of age and/or tooth loss on masticatory muscle function and size measured by MRI or ultrasound [6,7]. However, little is known about age-related changes in facial muscle size and function of the upper face [8].

The orbicularis oculi muscle is the sphincter muscle of the eyelids that blinks and closes the eyes. The homeostasis of the eyes surface environment is maintained by a delicate balance between tear production and proper tear drainage. The orbicularis oculi muscle that drives the flow of tears inward plays an important role in maintaining the thickness of the lacrimal layer on the cornea and distributing tears properly on the surface of the eye [9]. The appropriate number of blinks, amplitude (the difference between eyelid position at blink start and maximum eyelid closure), and velocity of the eyelid swing contribute to maintaining this homeostasis. Interestingly, there are close associations between spontaneous blinking behavior and physiological parameters. For example, it 
has been reported that spontaneous eyelid blinking rate is a surrogate indicator of the dopamine system [10].

The orbicularis oculi muscles may also affect facial expressions and appearance. Signs of facial aging may be caused by changes in soft tissues components (i.e., muscles and adipose tissue), including skin structure and function [11]. It is known that both intrinsic and extrinsic factors affect facial skin aging [12]. However, it is not well understood whether there is a link between a loss of facial muscle mass and function with increasing age. A large-scale cross-sectional study reported that ultrasound-measured facial soft tissue thickness was influenced by sex, body mass index (BMI), and age [13]. For example, the soft tissue thickness of the site centered on the eye pupil and just under the inferior orbital margin was higher in the high BMI group than in the low BMI group for both men and women, and these values are higher in older adults than young adults. A notable feature of aging in the upper face is baggy eyelids. A cross-sectional study on men and women reported that older individuals have smaller orbicularis oculi muscle thickness and larger orbital fat prolapse compared with young individuals, and there was a negative correlation between the two variables [14]. However, little is known about whether the orbicularis oculi muscle size and function are affected by aging and exercise training. The purpose of this review was to (1) introduce the performance characteristics of blinking activity in young and older adults, (2) discuss the influence of aging on the orbicularis oculi muscle in healthy adults, and (3) provide information about the effect of facial exercise training on orbicularis oculi muscle.

\section{The Search of Studies}

To search for articles that would achieve the purpose of this review, a keyword list was developed (e.g., aging, healthy adults, orbicularis oculi, eye blinking, facial muscle, eyelids, muscle thickness, fiber cross-sectional area, exercise training). An initial check of the keyword list was made against two databases (PubMed and Scopus) and a search engine (Google Scholar) and, where appropriate, additional keywords were added, and modifications to the keyword list were made. References from pertinent articles were cross-referenced to locate any further relevant articles.

\section{Influence of Age on the Function of Blinks}

The number of spontaneous blinks performed daily is estimated to be approximately 13,500 [15]. As mentioned above, an important function of eyelid blinking is to spread the tear film evenly over the ocular surface. Impaired eyelid blinking disrupts the balance between tear layer replenishment and evaporation, and thus disrupts ocular surface homeostasis. Analysis of eyelid movements by kinematic techniques provides important insights into the influence of aging on blinking activity. For example, Sun et al. [16] investigated kinematic patterns of upper eyelid movements using the magnetic scleral search coil technique in healthy adults aged from 40 to 89 years. Spontaneous blinks, i.e., unconscious and transient closure of both the upper and lower eyelids, were recorded over a period of 15 to $30 \mathrm{~min}$. The authors reported similar blink rates (blinks per minute) among each decade group (from $40-49$ years to $80-89$ years). Still, a significant age-related change in spontaneous blinks' amplitude and peak velocity was observed in both the down and up phases. Compared with 40-49 years of age, the amplitude was approximately $25 \%$ lower, and the peak velocity was approximately $30 \%$ lower in those $80-89$ years of age. The authors pointed out that one of the reasons for the lower blink amplitude with age may be related to ptosis (i.e., drooping eye) [16]. Similar results regarding the age-related changes in blinking performance were reported in other studies $[15,17,18]$.

Furthermore, it is observed that eyelid blinks do not always close the eye completely. A study reported that change in horizontal palpebral fissure length during spontaneous eyelid blink was lower in older adults (70-90 years of age) than in young adults (20-29 years of age) [19]. This result suggested that the difference in magnitude of orbicularis oculi muscle contraction between the open state before blinking and the eye closed by 
blinking may be small in older adults. In addition, it has been reported that the percentage of incomplete eye closure increases in older adults (range 51-77 years) compared with young adults (range 20-30 years) [17]. Together, these results suggest that the function of blinking is affected by age and that change may be due to decreases in strength and function of the orbicularis oculi muscles [19].

\section{Influence of Age on the Orbicularis Oculi Muscle Size}

One spontaneous blink takes about one-third of a second (approximately 100 milliseconds to close and approximately 200 milliseconds to open). Spontaneous blinks exhibit a temporally asymmetric pattern in which the closing action is much faster than the opening action. This difference in dynamics reflects the difference in myofiber type between the orbicularis oculi muscle, responsible for eyelid closure, and the levator palpebrae superioris muscle, responsible for eye opening [20]. The orbicularis oculi muscle is composed of approximately $90 \%$ type II myofibers, which is a relatively higher proportion compared with other facial muscles [21-23]. Limited studies have reported age-related differences in myofiber composition and size. For example, the percentage of type II myofibers (type IIa plus type IIx) was similar between young (mean $=88.7 \%$ ) and older $($ mean $=88.2 \%)$ adults. However, the cross-sectional area of type IIa myofibers was $11 \%$ lower in older adults ( $>70$ years old) compared with young adults ( $<50$ years old), although there were no differences in type I and type IIx myofiber cross-sectional areas between the two groups [24].

There are at least three defined sections of the orbicularis oculi muscle (from the outside: orbital, preseptal, and pretarsal), and the proportion of muscle fibers in the muscle is different in each section [24]. For example, the percentage of myofiber cross-sectional area of the pretarsal orbicularis was observed to be approximately $84 \%$, while other sections of this muscle were less than $50 \%$. Tissues other than myofibers in the muscle were mainly neurovascular, fibrous tissue, and adipose tissue [25]. Recently, Fukuda and Kajiya [26] reported that there was no significant difference in the mean myofiber cross-sectional area of the orbicularis oculi muscle between young and old adults (the measured section did not report). However, they observed that the percentage of myofiber areas in the orbicularis oculi muscle was lower in old adults than in young adults (the sample was 19 to 62 years old, but the age range of each young and old group was not reported).

Image processing techniques such as MRI, computed tomography (CT), and ultrasound are used to quantify the small muscles of the face. In the case of the ultrasound method, muscle thickness measurements were performed in a unit of $0.1 \mathrm{~mm}$, and the coefficient of variation and the minimal difference (absolute reliability) were, respectively, $7.7 \%$ and $0.25 \mathrm{~mm}$ for orbicularis oculi muscle thickness [27]. One study measured muscle volume of the right $\left(2959.9 \mathrm{~mm}^{3}\right)$ and left $\left(3024.7 \mathrm{~mm}^{3}\right)$ orbicularis oculi in healthy adults using MRI and found that this muscle is the symmetrical muscle compared with other facial muscles [28]. In regard to the influence of aging on the orbicularis oculi muscle size, Volk et al. [8] investigated the age-related differences in nine different facial muscles, including the orbicularis oculi, in 140 adults (70 men and 70 women) aged 21-93 years. Ultrasound orbicularis oculi muscle thickness was $16 \%$ smaller in women $(0.84 \mathrm{~mm})$ than in men $(1.00 \mathrm{~mm})$, which was consistent with a previous study [29]. The authors reported that there was a negative correlation $(r=-0.242, p=0.044)$ between age and muscle thickness of the orbicularis oculi in men but not in women $(r=-0.031, p=0.797)$. Okuda et al. [14] used CT to measure the orbicularis oculi muscle thickness in 34 adults (25 men and 9 women) aged 20-79 years. The participants were divided into three age groups: 20-29 years $(n=10)$, $30-54$ years $(n=11)$, and $55-79$ years $(n=13)$. There was a significant difference in the orbicularis oculi muscle thickness among the groups, with those aged 20-29 years having the highest muscle thickness $(2.7 \mathrm{~mm})$ and those aged $55-70$ years having the lowest muscle thickness $(1.7 \mathrm{~mm})$.

To our knowledge, only the two aforementioned studies exist for the influence of age on orbicularis oculi muscle thickness. The results of the study by Okura et al. included a mix of men and women, and the distribution of each age group is unknown. Thus, it is unclear 
whether the influence of aging on orbicularis oculi muscle thickness differs between men and women. In addition, the orbicularis oculi muscle has a large surface area that surrounds the eye [27], and age-related changes may vary depending on the site of measurement. Okura et al. [14] measured the muscle thickness of the lower eyelid (Figure 1, sagittal plane site-A) and found the aging effect on muscle size, while Volk et al. [8] measured the outside of the eye- the center of the upper and lower eyelids (Figure 1, transverse plane site-B) - and observed an aging effect on muscle size only in men. Additional research is needed to clarify this issue, including multi-site measurements and a large sample size of men and women. For reference, in order to detect a moderate effect $(\mathrm{d}=0.5$ at a power of 0.8 ) between men and women, there would need to be 64 participants of each sex. To detect a small effect $(\mathrm{d}=0.2)$, there would need to be approximately 400 men and 400 women.

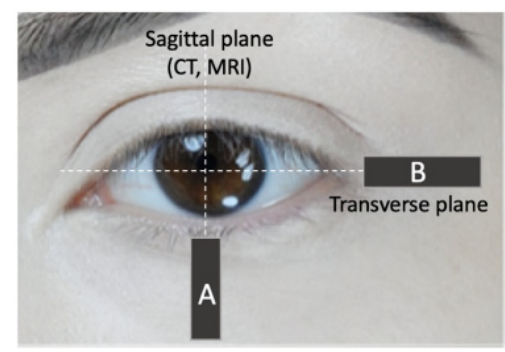

Figure 1. Measurement sites of orbicularis oculi muscle thickness. One study [13] measured the muscle thickness of the lower eyelid (sagittal plane site-A), while another study [8] measured the outside of the eye- the center of the upper and lower eyelids (transverse plane site-B).

\section{Effect of Facial Exercise on Orbicularis Oculi Muscle Size}

The facial muscles are expected to show similar adaptations as the limb muscles, but there is a lack research to support this thesis. For the facial muscles involved in mastication, it is possible to measure maximum muscular strength and use a device for exercise training [30-32]. By contrast, there is no established training protocol for the muscles of the upper face $[33,34]$. Kim et al. [35] introduced a resistance training protocol for the orbicularis oculi muscle using finger pressure on the soft tissue around the eyes. In particular, one method involves an individual putting the index fingers on the outside corners of the eyes in the upper eyelids and the middle fingers at the middle regions of the eyebrow. After that, the individual closes the eyes forcefully against fixed fingers. For the lower eyelid, the individual applies finger pressure on the soft tissue of the lower parts of the eye and similarly closes the eyes against fixed fingers. The authors reported the effects of this training program on skin firmness and elasticity but did not evaluate changes in muscle. Another study reported the effects of self-performed facial exercise training on the appearance of the face and neck, although they did not measure the changes in soft tissue thickness, including muscles [36]. To date, there has not been reported evidence of adaptation in the orbicularis oculi muscle after performing exercise training with the muscle. However, a case study showed the possibility of muscle hypertrophy of the orbicularis oculi following resistance exercise [37]. One man (37 years old) featured in the case study was a member of the circus and was capable of performing with the area around his eyes. He could pull a truck with his lower eyelids using metal hooks attached to his inferior orbital rim. His training consisted of hanging a $5 \mathrm{~kg}$ weight on the lower eyelid every day. The authors measured muscle thickness of the orbicularis oculi using MRI and reported that he had an orbicularis oculi muscle that was twice (5.0 $\mathrm{mm}$ in left) as thick as a person of the same age $(2.5 \mathrm{~mm})$. Although an initial value of his muscle size was not reported, it is inferred that the apparently large muscle size was acquired through daily training. However, we could not obtain the training variables (i.e., training intensity, volume, frequency, and training period) required to cause muscle hypertrophy of the orbicularis oculi muscle. 


\section{Summary}

In this review, we investigated the influence of aging on the orbicularis oculi muscle size and function. Spontaneously blinking behavior, which is an index of muscle function of the orbicularis oculi, certainly seems to be affected by aging. The muscle thickness of the orbicularis oculi tends to be low in older adults, but there are issues to be examined further, such as differences in sex and measurement positions. There was no study on the effect of exercise training; however, the results of a highly trained man indicate that the orbicularis oculi muscles might elicit muscle hypertrophy through non-traditional resistance exercise.

Author Contributions: T.A. conceived the idea, interpreted the findings, and drafted the initial manuscript. J.P.L. interpreted the findings and provided critical feedback, as well as edits and revisions to the manuscript. All authors approved the final version of this manuscript. All authors have read and agreed to the published version of the manuscript.

Funding: The authors received no financial support for the research, authorship, and publication of this article.

Institutional Review Board Statement: Not applicable.

Informed Consent Statement: Not applicable.

Data Availability Statement: Not applicable.

Conflicts of Interest: The authors declared no conflict of interest with respect to research, authorship, and publication of this article.

\section{References}

1. Geisler, C.; Braun, W.; Pourhassan, M.; Schweitzer, L.; Glüer, C.C.; Bosy-Westphal, A.; Müller, M.J. Gender-specific associations in age-related changes in resting energy expenditure (REE) and MRI measured body composition in healthy Caucasians. J. Gerontol. Ser. A Biomed. Sci. Med. Sci. 2016, 71, 941-946. [CrossRef]

2. Fortin, M.; Videman, T.; Gibbons, L.E.; Battie, M.C. Paraspinal muscle morphology and composition: A 15-yr longitudinal mag-netic resonance imaging study. Med. Sci. Sport. Exerc. 2014, 46, 893-901. [CrossRef]

3. Saladin, K. Anatomy \& Physiology: The Unity of Form and Function, 8th ed.; McGrawHill: New York, NY, USA, 2018 ; p. 319.

4. Abe, T.; Sakamaki, M.; Yasuda, T.; Bemben, M.G.; Kondo, M.; Kawakami, Y.; Fukunaga, T. Age-related, site-specific muscle loss in 1507 Japanese men and women aged 20 to 95 years. J. Sport. Sci. Med. 2011, 10, 145-150.

5. Abe, T.; Loenneke, J.P.; Thiebaud, R.S.; Fukunaga, T. Age-related site-specific muscle wasting of upper and lower extremities and trunk in Japanese men and women. Age 2014, 36, 813-821. [CrossRef] [PubMed]

6. Daboul, A.; Schwahn, C.; Bülow, R.; Kiliaridis, S.; Kocher, T.; Klinke, T.; Mundt, T.; Mourad, S.; Völzke, H.; Habes, M.; et al. Influence of age and tooth loss on masticatory muscles characteristics: A population based MR imaging study. J. Nutr. Health Aging 2018, 22, 829-836. [CrossRef] [PubMed]

7. Watanabe, Y.; Hirano, H.; Arai, H.; Morishita, S.; Ohara, Y.; Edahiro, A.; Murakami, M.; Pt, H.S.; Kikutani, T.; Suzuki, T. Relationship Between Frailty and Oral Function in Community-Dwelling Elderly Adults. J. Am. Geriatr. Soc. 2017, 65, 66-76. [CrossRef] [PubMed]

8. Volk, G.F.; Sauer, M.; Pohlmann, M.; Guntinas-Lichius, O. Reference values for dynamic facial muscle ultrasonography in adults. Muscle Nerve 2014, 50, 348-357. [CrossRef] [PubMed]

9. Sharma, A.; Hindman, H.B. Aging: A Predisposition to Dry Eyes. J. Ophthalmol. 2014, 2014, 1-8. [CrossRef]

10. Karson, C.N. Spontaneous Eye-Blink Rates and Dopaminergic Systems. Brain 1983, 106, 643-653. [CrossRef] [PubMed]

11. Windhager, S.; Mitteroecker, P.; Rupić, I.; Lauc, T.; Polašek, O.; Schaefer, K. Facial aging trajectories: A common shape pattern in male and female faces is disrupted after menopause. Am. J. Phys. Anthropol. 2019, 169, 678-688. [CrossRef] [PubMed]

12. Cannarozzo, G.; Fazia, G.; Bennardo, L.; Tamburi, F.; Amoruso, G.F.; Del Duca, E.; Nistico, S.P. A new 675 nm laser de-vice in the treatment of facial aging: A prospective observational study. Photobiomodul. Photomed. Laser Surg. 2021, 39, 118-122. [CrossRef] [PubMed]

13. De Greef, S.; Claes, P.; Vandermeulen, D.; Mollemans, W.; Suetens, P.; Willems, G. Large-scale in-vivo Caucasian facial soft tissue thickness database for craniofacial reconstruction. Forensic Sci. Int. 2006, 159, S126-S146. [CrossRef]

14. Okuda, I.; Irimoto, M.; Nakajima, Y.; Sakai, S.; Hirata, K.; Shirakabe, Y. Using Multidetector Row Computed Tomography to Evaluate Baggy Eyelid. Aesthet. Plast. Surg. 2012, 36, 290-294. [CrossRef] [PubMed]

15. Peshori, K.R.; Schicatano, E.J.; Gopalaswamy, R.; Sahay, E.; Evinger, C. Aging of the trigeminal blink system. Exp. Brain Res. 2001, 136, 351-363. [CrossRef] [PubMed]

16. Sun, W.S.; Baker, R.S.; Chuke, J.C.; Rouholiman, B.R.; A Hasan, S.; Gaza, W.; Stava, M.W.; Porter, J.D. Age-related changes in human blinks. Passive and active changes in eyelid kinematics. Investig. Ophthalmol. Vis. Sci. 1997, 38, 92-99. 
17. Sforza, C.; Rango, M.; Galante, D.; Bresolin, N.; Ferrario, V.F. Spontaneous blinking in healthy persons: An optoelectronic study of eyelid motion. Ophthalmic Physiol. Opt. 2008, 28, 345-353. [CrossRef] [PubMed]

18. Coors, A.; Merten, N.; Ward, D.D.; Schmid, M.; Breteler, M.M.B.; Ettinger, U. Strong age but weak sex effects in eye movement performance in the general adult population: Evidence from the Phineland Study. Vis. Res. 2021, 178, 124-133. [CrossRef]

19. DeAngelis, K.D.; Rider, A.; Potter, W.; Jensen, J.; Fowler, B.T.; Fleming, J.C. Eyelid Spontaneous Blink Analysis and Age-Related Changes Through High-Speed Imaging. Ophthalmic Plast. Reconstr. Surg. 2019, 35, 487-490. [CrossRef] [PubMed]

20. Kwon, K.A.; Shipley, R.J.; Edirisinghe, M.; Ezra, D.G.; Rose, G.; Best, S.M.; Cameron, R.E. High-speed camera characterization of voluntary eye blinking kinematics. J. R. Soc. Interface 2013, 10, 20130227. [CrossRef] [PubMed]

21. Happak, W.; Burggasser, G.; Gruber, H. Histochemical characteristics of human mimic muscles. J. Neurol. Sci. 1988, 83, 25-35 [CrossRef]

22. Goodmurphy, C.W.; Ovalle, W. Morphological study of two human facial muscles: Orbicularis oculi and corrugator supercilia. Clin. Anat. 1999, 12, 1-11. [CrossRef]

23. Hwang, K.; Huan, F.; Kim, D.J. Muscle Fiber Types of Human Orbicularis Oculi Muscle. J. Craniofac. Surg. 2011, 22, 1827-1830. [CrossRef]

24. Cheng, N.C.; Liao, S.L.; Wang, I.J.; Lin, I.C.; Tang, Y.B. Fiber type and myosin heavy chain compositions of adult pretarsal orbicularis oculi muscle. J. Mol. Histol. 2007, 38, 177-182. [CrossRef] [PubMed]

25. Costin, B.R.; Plesec, T.P.; Kopplin, L.J.; Chundury, R.V.; McBride, J.M.; Levine, M.R.; Perry, J.D. Regional variations in orbicularis oculi histology. Ophthalmic Plast. Reconstr. Surg. 2015, 31, 325-327. [CrossRef] [PubMed]

26. Fukuda, K.; Kajiya, K. Age-related structural alterations of skeletal muscles and associated capillaries. Angiogenesis 2020, 23, 79-82. [CrossRef]

27. Abe, T.; Spitz, R.W.; Wong, V.; Viana, R.B.; Yamada, Y.; Bell, Z.W.; Chatakondi, R.N.; Loenneke, J.P. Assessments of facial muscle thickness by ultrasound in younger adults: Absolute and relative reliability. Cosmetics 2019, 6, 65. [CrossRef]

28. Volk, G.F.; Karamyan, I.; Klingner, C.M.; Reichenbach, J.R.; Guntinas-Lichius, O. Quantitative magnetic resonance imaging volumetry of facial muscles in healthy patients with facial palsy. Plast. Reconstr. Surg. Glob. Open 2014, 2, e173. [CrossRef] [PubMed]

29. Abe, T.; Wong, V.; Spitz, R.W.; Viana, R.B.; Bell, Z.W.; Yamada, Y.; Chatakondi, R.N.; Loenneke, J.P. Influence of sex and resistance training status on orofacial muscle strength and morphology in healthy adults between the ages of 18 and 40: A cross-sectional study. Am. J. Hum. Biol. 2020, 32, e23401. [CrossRef] [PubMed]

30. Viana, R.B.; da Sliva, W.F.; de Lira, C.A.B. Effects of chewing training on orofacial and cognitive function in healthy individuals: A systematic review. Cosmetics 2020, 7, 23. [CrossRef]

31. Abe, T.; Viana, R.B.; Wong, V.; Bell, Z.W.; Spitz, R.W.; Yamada, Y.; Thiebaud, R.S.; Loenneke, J.P. The influence of training variables on lingual strength and swallowing in adults with and without dysphagia. JCSM Clin. Rep. 2020, 5, $29-41$.

32. Wong, V.; Abe, T.; Spitz, R.W.; Bell, Z.W.; Yamada, Y.; Chatakondi, R.N.; Loenneke, J.P. Effects of Age, Sex, Disease, and Exercise Training on Lip Muscle Strength. Cosmetics 2020, 7, 18. [CrossRef]

33. Van Borsel, J.; De Vos, M.C.; Bastiaansen, K.; Welvaert, J.; Lambert, J. The effectiveness of facial exercise for facial rejuvenation: A systematic review. Aesthet. Surg. J. 2014, 34, 22-27. [CrossRef] [PubMed]

34. Abe, T.; Loenneke, J.P. The Influence of Facial Muscle Training on the Facial Soft Tissue Profile: A Brief Review. Cosmetics 2019, 6, 50. [CrossRef]

35. Kim, K.; Jeon, S.; Kim, J.-K.; Hwang, J.S. Effects of Kyunghee Facial Resistance Program (KFRP) on mechanical and elastic properties of skin. J. Dermatol. Treat. 2015, 27, 191-196. [CrossRef]

36. Alam, M.; Walter, A.J.; Geisler, A.; Roongpisuthipong, W.; Sikorski, G.; Tung, R.; Poon, E. Association of Facial Exercise With the Appearance of Aging. JAMA Dermatol. 2018, 154, 365-367. [CrossRef] [PubMed]

37. Hassan, H.A.; Ramli, N.M.; Fong, K.C.S.; Goh, K.J. MRI findings of orbicularis oculi hypertrophy due to heavy resistance training on the inferior orbital rim. Neurol. Asia 2013, 18, 427-429. 